\title{
Ultrasound-Enhanced Drug Transport and Distribution in the Brain
}

\author{
Ying Liu, ${ }^{1}$ Sumit Paliwal, ${ }^{2}$ Krystof S. Bankiewicz, ${ }^{3}$ John R. Bringas, ${ }^{3}$ Gill Heart, ${ }^{4}$ \\ Samir Mitragotri, ${ }^{2,5}$ and Mark R. Prausnitz ${ }^{1,5}$
}

Received 4 September 2009; accepted 13 May 2010; published online 8 June 2010

\begin{abstract}
Drug delivery in the brain is limited by slow drug diffusion in the brain tissue. This study tested the hypothesis that ultrasound can safely enhance the permeation of drugs in the brain. In vitro exposure to ultrasound at various frequencies $(85 \mathrm{kHz}, 174 \mathrm{kHz}$, and $1 \mathrm{MHz})$ enhanced the permeation of tritiumlabeled molecules with molecular weight up to $70 \mathrm{kDa}$ across porcine brain tissue. A maximum enhancement of 24-fold was observed at $85 \mathrm{kHz}$ and $1,200 \mathrm{~J} / \mathrm{cm}^{2}$. In vivo exposure to $1-\mathrm{MHz}$ ultrasound further demonstrated the ability of ultrasound to facilitate molecule distribution in the brain of a nonhuman primate. Finally, ultrasound under conditions similar to those used in vivo was shown to cause no damage to plasmid DNA, siRNA, adeno-associated virus, and fetal rat cortical neurons over a range of conditions. Altogether, these studies demonstrate that ultrasound can increase drug permeation in the brain in vitro and in vivo under conditions that did not cause detectable damage.
\end{abstract}

KEY WORDS: brain tumor; chemotherapy; drug delivery; therapeutic ultrasound; tissue permeability.

\section{INTRODUCTION}

The development of therapies to treat brain diseases including brain cancer has been limited by the failure of efficient drug delivery into the brain due to the blood-brain barrier (BBB) (1). Several approaches have been developed to successfully bypass the BBB and deliver drugs into the brain, but their ability to increase the depth of drug penetration or distribution within the brain is still limited (1). Controlled release devices including plastic drug reservoirs (2), implantable pumps (3), and biodegradable polymers $(4,5)$ have been designed to provide drug diffusion for an extended time, but diffusion distance has been limited to less than a few millimeters from the point of drug administration due to very low diffusivity $(6,7)$. Drug diffusion also requires a high concentration gradient, and such high drug concentrations often lead to neuronal toxicity (8).

Convection-enhanced delivery (CED) provides a convective driving force to flow drugs deeper into tissue (9-11). CED has been shown to be effective for delivering large molecules, including DNA and viral gene therapy vectors. Clinical trials

Ying Liu and Sumit Paliwal contributed equally to this study.

${ }^{1}$ School of Chemical and Biomolecular Engineering, Georgia Institute of Technology, Atlanta, Georgia 30332-0100, USA.

${ }^{2}$ Department of Chemical Engineering, University of California, Santa Barbara, California 93106, USA.

${ }^{3}$ Department of Neurological Surgery, Brain Tumor Research Center, University to California, San Francisco, California 94103, USA.

${ }^{4}$ CytoDome, Inc, Atlanta, Georgia 30342, USA.

${ }^{5}$ To whom correspondence should be addressed. (e-mail: samir@ engineering.ucsb.edu; prausnitz@gatech.edu) have been conducted to apply CED to the treatment of brain cancer (11). However, poor drug distribution limits this technique due to the considerable resistance to flow within densely packed brain tissue. To reach larger volumes in the human brain, it is often necessary to infuse drugs for longer periods of time, i.e., from hours to days, making this approach impractical. Overall, current methods have chiefly focused on strategies to deliver drugs into the brain by breaching the BBB but have been limited in their ability to increase the depth of drug penetration or distribution within the brain.

In this study, we propose the hypothesis that ultrasound (US) can facilitate drug distribution in the brain. US-based drug delivery applications are increasingly being tested, and several successful studies in animals and humans have been demonstrated, with a few applications already entering in the clinical setting (12). US has been shown to increase drug transport into and across a number of tissues, including skin $(13,14)$, kidney (15), heart (16), and blood clots (17). Of particular interest, US-mediated disruption of the BBB has been previously shown to significantly enhance drug delivery to the brain $(18,19)$. It was shown that using low-energy focused US pulses combined with an US contrast agent could reversibly disrupt the BBB in the US-targeted regions of the brain without adverse effects in the brain tissue. A variety of therapeutic agents including chemotherapeutic drugs and antibodies were shown to be effectively delivered into the brain with US exposure at frequencies suitable for transcranial usage $(19,20)$. The mechanism is believed to involve ultrasonic non-thermal bioeffects, particularly induction of acoustic cavitation and its disruptive interactions with the brain vasculature to facilitate increase in blood vessel permeability to drug molecules (21). Other cellular-level studies exploring changes in microscopic histological features 
of the sonicated blood vessels have also been conducted (22). However, a systematic study investigating the effects of US on the increase in tissue permeability and, therefore, increased distribution of drugs in the brain at a macroscopic tissue-level has not been performed. Furthermore, in the context of brain drug delivery, the effects of US exposure on changes in the bioactivity of various therapeutic agents have not been evaluated.

In this study, we show that US, applied at various frequencies and energy densities, can significantly enhance the transport and distribution of several molecules across both normal and tumor brain tissue in vitro and facilitate the distribution of gadolinium-encapsulated liposomes in targeted regions of the brain in vivo. We also test the hypothesis that US conditions suitable for increased brain delivery do not damage the functionality of drugs and delivery carriers including plasmid DNA, siRNA, and adeno-associated virus and do not reduce the viability of cortical neurons and the integrity of brain tissues. These studies indicate that USassisted drug delivery to the brain offers a promising treatment strategy which effectively addresses the issue of limited penetration of drugs post-delivery within the brain tissue.

\section{MATERIALS AND METHODS}

\section{In Vitro Brain Delivery}

Experimental setup. Excised porcine brain tissue was procured in frozen form (LyChron LLC, Mountain View, California, USA), stored at $-80^{\circ} \mathrm{C}$, and later defrosted at room temperature prior to the experiment. Cylindrical sagittal sections of brain $(1.8 \mathrm{~cm}$ in diameter and $2 \mathrm{~mm}$ in thickness) were carefully cut and mounted onto a custommade diffusion cell consisting of a donor and a receiver compartment (Fig. 1) with a cross-sectional area of $2.54 \mathrm{~cm}^{2}$. The receiver compartment was filled with a sodium/potassium phosphate-buffered saline (PBS; Sigma-Aldrich, St. Louis, Missouri, USA) prepared in MilliQ ${ }^{\circledR}$ ultrapure water (Millipore, Billerica, Massachusetts, USA) consisting of $0.01 \mathrm{M}$ phosphate and $0.137 \mathrm{M} \mathrm{NaCl}$. Separate solutions of different ${ }^{3} \mathrm{H}$-labeled model molecules, including water, mannitol, inulin, and dextran $(70 \mathrm{kDa}$; ART-194A, ART118, ART-278, and ART-215; American Radio Chemicals, St. Louis, Missouri, USA) and bischloroethyl-nitrosourea (BCNU; MT-1644, Moravek Biochemicals, Brea, California, USA), were prepared in PBS at a concentration of $1 \mu \mathrm{Ci} / \mathrm{mL}$ and filled into the donor compartment in separate experiments.

Frozen human brain 9-L tumors grown under rat skin with Institutional Animal Care and Use Committees (IACUC) approval were kindly provided by the Brain Tumor Research Laboratory at the Johns Hopkins University. Similar to porcine brain tissue, tumor tissues were also cut to $1.8 \mathrm{~cm}$ in diameter and $2 \mathrm{~mm}$ in thickness and studied as described above.

US application. Three custom-built, non-focused, piezoelectric transducers (CytoDome Inc., Atlanta, Georgia, USA) with operating frequencies of $85 \mathrm{kHz}, 174 \mathrm{kHz}$, and $1 \mathrm{MHz}$ were used. The $1-\mathrm{MHz}$ transducer was calibrated using an HNR-0500 hydrophone (Onda Corporation, Sunnyvale, California, USA), and the $85-$ and $174-\mathrm{kHz}$ transducers were calibrated using a TC4038 hydrophone (Reson Inc., Goleta, California, USA). Calibration for each transducer was performed in the Fresnel region of the US beam using the lateral beam profile at a distance of $0.42 \mathrm{~cm}$ from the face of the transducer. Pressures and energy densities in this paper are reported as spatial and temporal average values. A signal generator (Agilent 33120A, Palo Alto, California, USA) along with an amplifier (CytoDome) was used to drive the transducers. The electric power and signal waveform fed to the transducers were continuously measured using an oscilloscope (Tektronix TDS 224, Beaverton, Oregon, USA). A step-up tuning transformer (1:2.8) was connected in series with each transducer to optimize its performance (Fig. 1). US was applied in pulsed form at a constant burst rate (100 bursts/s for $85-$ and $174-\mathrm{kHz}$ transducers and 1 bursts/s for $1-\mathrm{MHz}$ transducer). The duty cycle was varied in the range of $1 \%$ to $7 \%$; however, for most sonication conditions, it was fixed at 5\% unless otherwise stated. "Sham" exposure experiments were carried out in the same apparatus without US.

The US transducer, with a cross-sectional area of $2.54 \mathrm{~cm}^{2}$, was secured in the donor compartment. US was applied for a total of $4 \mathrm{~h}$ at room temperature in all experiments. Samples were collected from the receiver chamber at regular intervals up to $4 \mathrm{~h}$ during the experiment (with or without US), and tracer molecule concentration was determined using a liquid scintillation counter (Packard, Meriden, Connecticut, USA). At the end of $4 \mathrm{~h}$, effective tissue permeability, $P$, was obtained as follows:

$$
P=\frac{V_{\mathrm{R}}}{A C_{\mathrm{D}}} \frac{d C_{\mathrm{R}}}{d t}
$$

where $V_{\mathrm{R}}$ is volume of the receiver chamber $\left(1.02 \mathrm{~cm}^{3}\right), A$ is brain cross-sectional area for transport $\left(2.54 \mathrm{~cm}^{2}\right), C_{\mathrm{D}}$ is donor concentration $(1 \mu \mathrm{Ci} / \mathrm{mL}), C_{\mathrm{R}}$ is receiver concentration, and $t$ is time. Permeation enhancement due to US exposure was calculated by dividing $P$ by its value in the absence of US.

Electrical conductivity measurements. Electrical conductivity $(\sigma)$ of the brain tissue was measured during US exposure as a surrogate measure for tissue permeability. A potential $(V)$ of $100 \mathrm{mV}$ rms AC at $10 \mathrm{~Hz}$ was applied across the tissue using a signal generator (Agilent 33120A). The current $(I)$ flowing through the tissue was measured using a multimeter (Fluke 189 True RMS Multimeter, Everett, Washington, USA; Fig. 1). Conductivity was calculated as follows:

$$
\sigma=(I / V) \times(L / A),
$$

in which $L$ is thickness of the tissue $(2 \mathrm{~mm})$ and $A$ is crosssectional area $\left(2.54 \mathrm{~cm}^{2}\right)$, assuming that the conductance at $10 \mathrm{~Hz}$ is the same as the DC conductance (23). Conductivity enhancement due to US exposure was calculated by dividing $\sigma$ by its value in the absence of US.

Tissue histology. Brain samples were collected following sonication at $85 \mathrm{kHz}, 174 \mathrm{kHz}$, and $1 \mathrm{MHz}$ frequency and at an energy density of $1,250 \mathrm{~J} / \mathrm{cm}^{2}$. Control samples were also collected from the tissues not exposed to US. Tissues were fixed in $10 \%$ formalin for $24 \mathrm{~h}$ and embedded in paraffin. Five-micrometer-thick tissue sections were stained with 


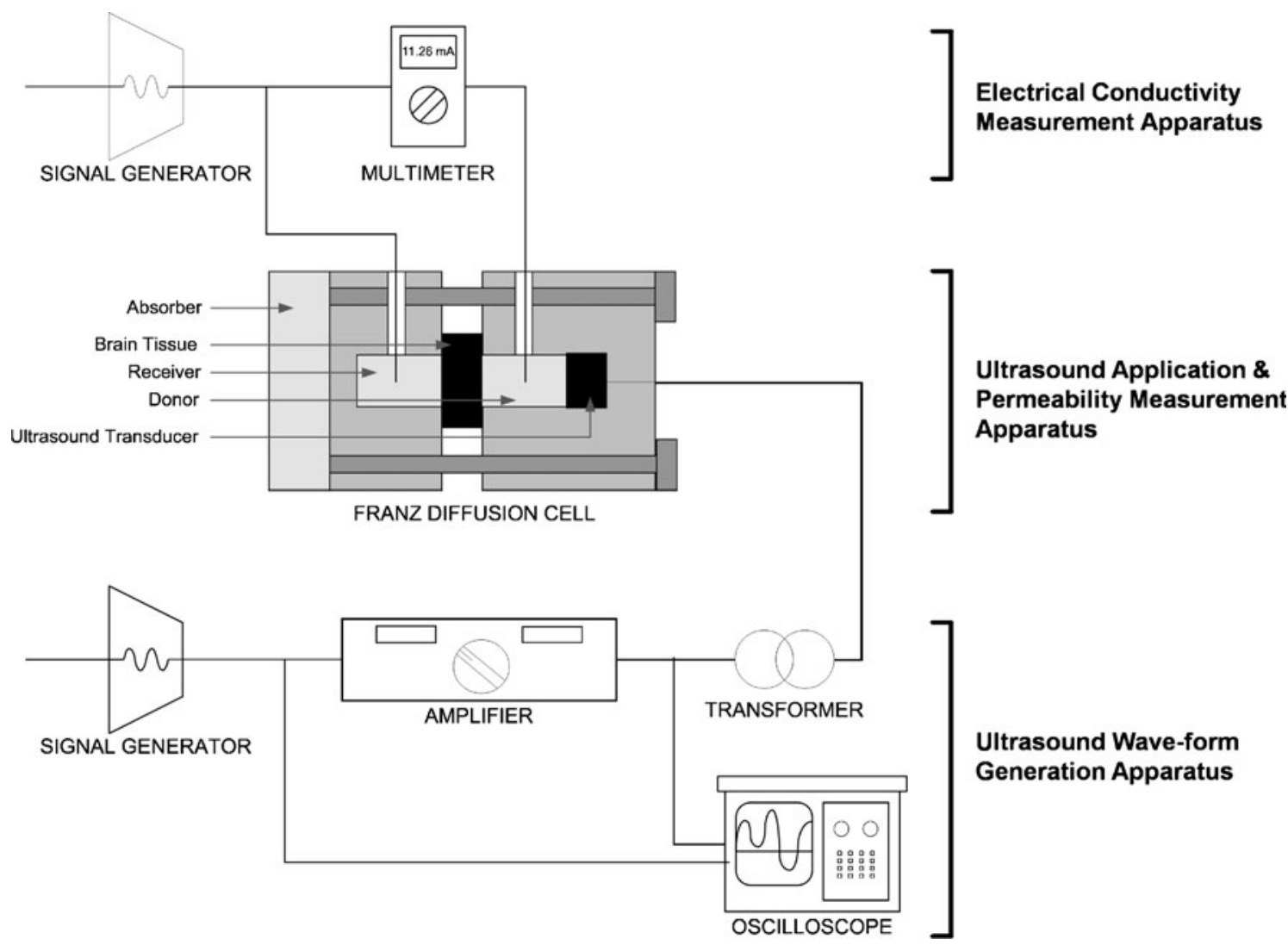

Fig. 1. In vitro brain slice permeability experimental setup containing (a) electrical conductivity measurement apparatus to determine brain slice conductivity, (b) the US application and permeability measurement apparatus to expose brain tissue to US and measure changes in tissue permeability to various molecules, and (c) the US waveform generation apparatus to control US conditions

hematoxylin-eosin for structural analysis (Mass Histology Service, Worcester, Massachusetts, USA).

\section{In Vivo Brain Delivery}

We applied US through a craniotomy window in this study to avoid the complexities of transmitting US through the skull, which can be accomplished, for example, using lowfrequency, large surface area phased arrays and US wave distortion correction methods $(24,25)$.

US device. A custom-built US device for implantation into the primate brain including a non-focused piezoelectric $1-\mathrm{MHz}$ transducer was fabricated by CytoDome as shown in Fig. 2a. The transducer was calibrated as described previously. The device was tested for magnetic resonance imaging (MRI) compatibility and found compatible, so that the MRI results would not be affected by the US device. Device temperature as a function of emitted power was also tested, and the US conditions that did not affect the temperature change (i.e., $<<1^{\circ} \mathrm{C}$ ) were chosen: pressure of $1.24 \mathrm{MPa}$ (mechanical index $(\mathrm{MI})=1.24)$, pulse length of $20 \mu \mathrm{s}$, and duty cycle of $2.5 \%$. A polyimide tube was inserted in the middle of the transducer for liposome injection.

Liposome preparation. As described previously (26), liposomes containing MRI contrast agent were composed of 1,2-dioleoyl-sn-glycero-3-phosphocholine (Avanti Polar Lipids, Alabaster, Alabama, USA), cholesterol (Calbiochem, San Diego, California, USA), and 1,2-distearoyl-sn-glycero-3[methoxy(polyethylene glycol)-2000] (PEG-DSG; NOF Corporation, Tokyo, Japan) with a molar ratio of 3:2:0.3. The lipids were dissolved in chloroform/methanol $(90: 10 \mathrm{v} / \mathrm{v})$ and then the solvent was removed by rotary evaporation, resulting in a thin lipid film. The lipid film was dissolved in ethanol and heated to $60^{\circ} \mathrm{C}$. A commercial United States Pharmacopeia solution of $0.5 \mathrm{M}$ Gadoteridol (10-(2-hydroxy-propyl)1,4,7,10-tetraazacyclododecane-1,4,7-triacetic acid; Prohance; Bracco Diagnostics, Princeton, New Jersey, USA) was heated to $60^{\circ} \mathrm{C}$ and injected rapidly into the ethanol/lipid solution. Unilamellar liposomes were formed by extrusion (Lipex; Northern Lipids, Vancouver, British Columbia, Canada) with 15 passes through double-stacked polycarbonate membranes (Whatman Nucleopore, Clifton, New Jersey, USA) with a

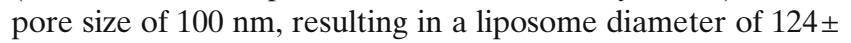
$24.4 \mathrm{~nm}$ as determined by quasi-elastic light scattering (N4Plus particle size analyzer, Beckman Coulter, Fullerton, California, USA). Unencapsulated Gadoteridol was removed with a Sephadex G-75 (Sigma, St. Louis, Missouri, USA) sizeexclusion column eluted with pH6.5 HEPES-buffered saline (5 mM HEPES, $135 \mathrm{mM} \mathrm{NaCl}$, pH adjusted with $\mathrm{NaOH}$ ).

Liposomes loaded with rhodamine for histological studies were formulated using the same lipid composition and preparation method as the Gadoteridol-containing liposomes, 
a
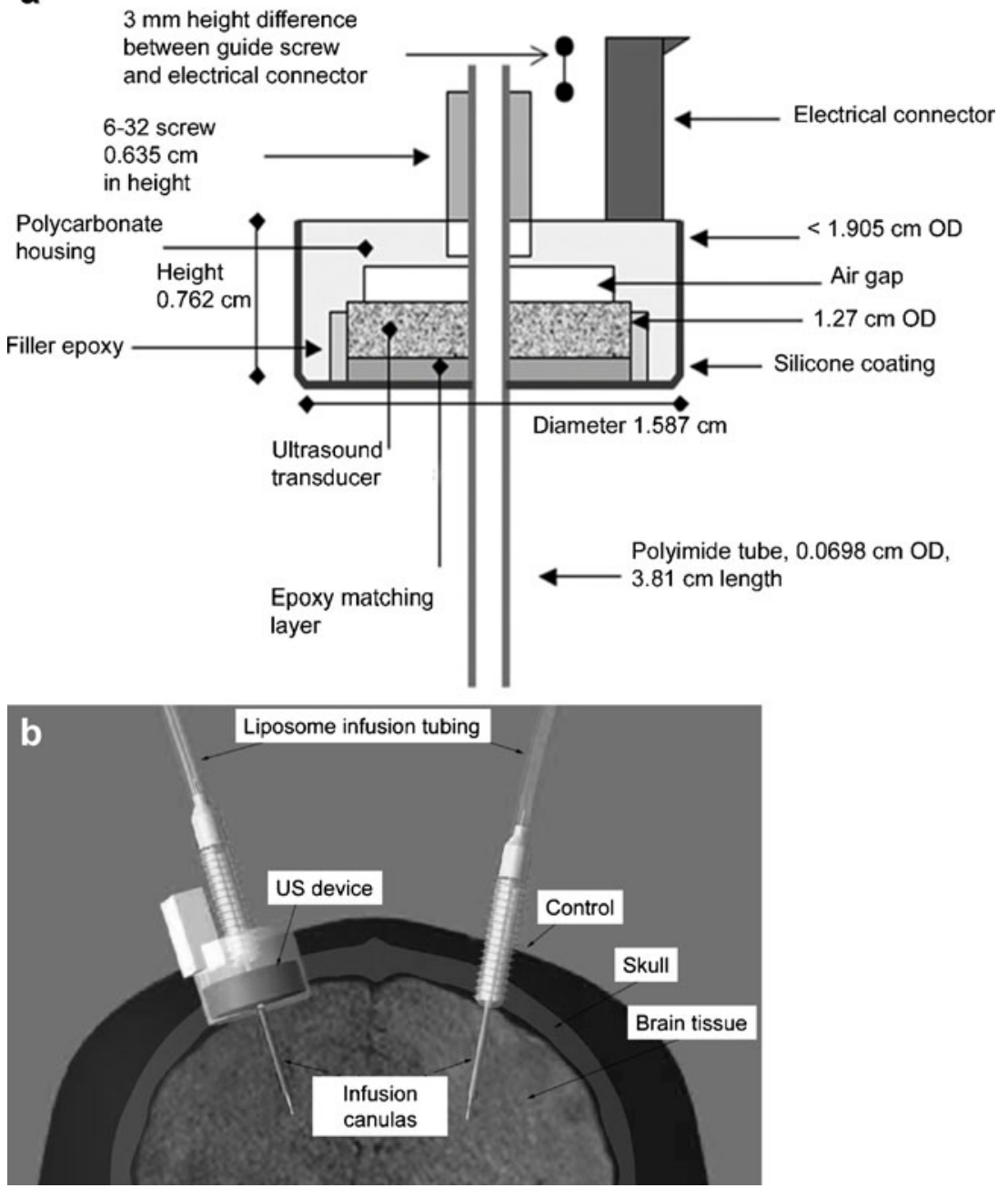

Fig. 2. In vivo delivery experimental setup. a Schematic of US device with infusion cannula for in vivo study. b Schematic of the experimental setup for liposomal distribution, where US was applied to the left hemisphere and not to the right hemisphere

except that the lipids were hydrated directly with $20 \mathrm{mM}$ sulforhodamine B (Sigma) in pH6.5 HEPES-buffered saline by six successive cycles of rapid freezing and thawing rather than by ethanol injection. The sulforhodamine B liposomes had a diameter of $90 \pm 30 \mathrm{~nm}$ (used alone for histological analysis) or $115 \pm 40 \mathrm{~nm}$ (used for co-infusion with the Gadoteridol-containing liposomes in the MRI-monitoring study).

Experimental subject and implantation. The experimental protocol was reviewed and approved by IACUC at the University of California San Francisco (UCSF). A cynomolgus monkey (Animal F21339M, male, $6.5 \mathrm{~kg}$ ) was identified as a suitable liposomal infusion candidate (26) and received a baseline MRI scan to generate surgical coordinates. Intracranial procedures were performed to implant MRI compatible guide cannula within the corona radiata. A 26G MRI compatible guide cannula (26) was stereotactically introduced into the right hemisphere $(32 \mathrm{~mm}$ anterior from the ear canal, $10 \mathrm{~mm}$ lateral to midline, and a depth of $10 \mathrm{~mm}$ ventral to the cortex). The left hemisphere received the US device with guide cannula using the same coordinates. Each device was secured to the skull using dental acrylic (Lang Dental Manufacturing, Wheeling, Illinois, USA; Fig. 2b).

MRI acquisition and volume quantification. MR images were acquired in collaboration with the UCSF Magnetic Resonance Imaging Science Center (MRSC). As described previously (26), T1-weighted images of the primate's brain were acquired on a 1.5-T Signa LX scanner (GE Medical Systems, Waukesha, Wisconsin, USA) with a 5-in. surface coil. Prior to inserting infusion catheters, baseline spoiled gradient echo (SPGR) images were taken: repetition time/echo time/flip angle $=28 \mathrm{~ms} / 8 \mathrm{~ms} / 40^{\circ}$, number of excitations $=4$, matrix $=256 \times$ 192 , field of view $=16 \mathrm{~cm} \times 12 \mathrm{~cm}$, and slice thickness $=1 \mathrm{~mm}$. These parameters resulted in a $0.391-\mathrm{mm}^{3}$ voxel volume. Once the catheters were inserted and the infusion commenced, SPGR scans were taken consecutively throughout the infusion. The scan time was dependent on the number of slices needed to cover the extent of infusion but was approximately $10 \mathrm{~min}$. The volume of liposomal distribution during and after infusion 
was quantified by subtracting the infusion baseline images from the final infusion images and removing the background intensities in the brain. The image was segmented for liposomal distributions by a contouring function (iPlan Flow software, BrainLAB, Westchester, Illinois, USA) that created a region of interest for the calculation of the distribution volume, $V_{\mathrm{d}}(26)$.

Liposome infusion. After a 4-week surgical recovery period after device placement or between study sessions, the animal was sedated, placed in a transport box, and transferred to the MRSC. Under isoflurane anesthesia, the animal's head was positioned in an MRI-compatible stereotactic frame. The animal was transferred into the gantry of the 1.5-T Signa LX scanner. After a pre-infusion MRI scan, two non-ferromagnetic needle cannulas (26) (connected to beehive micro-infusion pumps; Bioanalytical Systems, West Lafayette, Indiana, USA) were aseptically introduced into targeted regions of the brain using the implanted guide cannula entry ports. Infusion procedures were initiated simultaneously in two sites of the brain while MRI was continuously acquired. An initial infusion rate of $0.1 \mu \mathrm{L} / \mathrm{min}$ was applied and increased at 10 -min intervals to a maximum rate of $3.0 \mu \mathrm{L} / \mathrm{min}$. After $30-50 \mu \mathrm{L}$ of liposomes was delivered, the infusion rate was fixed at $3.0 \mu \mathrm{L} / \mathrm{min}$ for trial I and $0.1 \mu \mathrm{L} / \mathrm{min}$ for trials II and III in both hemispheres to maintain positive pressure, and an MRI scan was acquired to verify adequate gd-lipo distribution into the corona radiata. US was administered on the left hemisphere at several time points during infusion and at the completion of infusion. MRI was acquired prior to and immediately following each US session. At the completion of the study, the animal was removed from the MRI gantry, extubated, monitored for full recovery from anesthesia, placed in its transfer cage, and transported back to the animal facility.

Necropsy and histology. After all study sessions were completed, the animal was transported to the necropsy room and euthanized with an overdose of pentobarbital (IV). The brain was harvested and coronally sliced into 9-mm blocks. Each tissue block was freshly frozen in dry-ice cooled isopentane and processed for histology. Relevant blocks containing gadolinium and rhodamine infused sites were sliced into $300-\mu \mathrm{m}$ sections on a microtome and mounted onto slides for microscopy.

\section{In Vitro Safety and Drug Bioactivity}

Cell culture. Rat cortical neurons were freshly harvested from fetal E18 Sasco Sprague-Dawley rats (Charles River Laboratories, Wilmington, Massachusetts, USA) with IACUC approval as previously described (27) and suspended in Neurobasal medium containing 2\% B-27 and $500 \mu \mathrm{M}$ L-glutamine (Gibco, Invitrogen, Carlsbad, California, USA) at a concentration of $1 \times 10^{6}$ cells $/ \mathrm{mL}$. DU145 human prostate cancer cells (American Type Culture Collection, Manassas, Virginia, USA, item no. HTB-81) in RPMI-1640 medium and human HT-1080 fibrosarcoma cells (American Type Culture Collection, item no. CCL-121) in DMEM medium were cultured as monolayers in a humidified atmosphere of $95 \%$ air and $5 \% \mathrm{CO}_{2}$ at $37^{\circ} \mathrm{C}$. The medium was supplemented with $10 \%$ heat-inactivated fetal bovine serum (FBS; Atlanta Biologicals, Atlanta, Georgia, USA) and $1 \%$ penicillin/streptomycin (Cellgro, Mediatech, Herndon, Virginia, USA).

US apparatus and exposure. To generate a range of acoustic pressures for a broad assessment of possible damaging effects of US, a focused 1.1-MHz transducer (model no. H-101, Sonic Concepts, Woodinville, Washington, USA) was submerged in de-ionized water at $37^{\circ} \mathrm{C}$ to sonicate a $375-\mu \mathrm{L}$ sample held within a disposable micropipette (Samco, San Fernando, California, USA), as described previously (28). The transducer was calibrated by a PVDF membrane hydrophone (NTR Systems, Seattle, Washington, USA, model no. HMA-0200) at $1 \mathrm{~cm}$ from the transducer. Sonication was carried out at pressures $(p)$ ranging from $0 \mathrm{MPa}$ (i.e., "sham" exposure) to $2 \mathrm{MPa}$, and the total treatment time $(t)$ was either 10 or 60 min with a burst length of $750 \mu$ s at a $2.5 \%$ duty cycle $(D)$. Therefore, the corresponding energy density $(J)$ ranged from 0 to $12,000 \mathrm{~J} / \mathrm{cm}^{2}$, which was calculated as

$$
J=t \times D \times \frac{\left(\frac{p}{\sqrt{2}}\right)^{2}}{\rho \times u},
$$

where $\rho$ is the density of water $(1 \mathrm{~g} / \mathrm{mL})$ and $u$ is the speed of sound in water $(1,500 \mathrm{~m} / \mathrm{s})$.

Samples exposed to US included plasmid DNA, siRNA, adeno-associated virus, and neuronal cells. DNA samples were prepared by diluting plasmid gWizTM-GFP (Aldevron, Fargo, North Dakota, USA) that encodes green fluorescent protein (GFP) to a final concentration of $16 \mu \mathrm{g} / \mathrm{mL}$ in OptiMEM medium (Gibco). Survivin-siRNA (Silencer predesigned siRNA, Ambion, Austin, Texas, USA) was diluted to a final concentration of $100 \mathrm{nM}$ in Opti-MEM medium.

Adeno-associated virus (provided courtesy of Dr. Athanasios Sambanis, Georgia Institute of Technology, Atlanta, Georgia, USA), prepared as described previously (29), was diluted in DMEM medium supplemented with $2 \%$ FBS to a concentration of $1.4 \times 10^{6}$ infectious units $/ \mathrm{mL}$.

Rat cortical neurons were suspended in DMEM at a concentration of $1 \times 10^{6}$ cells $/ \mathrm{mL}$. Definity US contrast agent (Lantheus Medical Imaging, North Billerica, Massachusetts, USA) was added to some samples at a concentration of 0.2 vol. $\%$ to serve as cavitation nucleation sites.

Sample analysis. Possible damaging effects of US were assessed by measuring possible reductions in DNA's ability to transfect cells, siRNA's ability to knockdown protein expression, adeno-associated virus' ability to transduce cells, and cortical neuron viability after sonication. To measure DNA transfection efficiency, DU145 cells were mixed with sonicated plasmid DNA and Lipofectamine 2000 (Invitrogen) according to the procedure recommended by the manufacturer. After incubation in the growth conditions in full culture medium for $24 \mathrm{~h}$, cells were trypsinized, suspended in $300 \mu \mathrm{L}$ PBS, and placed on ice until analysis by flow cytometry (BD LSR, Becton Dickinson, San Jose, California, USA). Transfection efficiency was measured by determining the percentage of cells with green fluorescence due to GFP expression greater than untreated control cells.

To measure survivin knockdown, DU145 cells were transfected with sonicated siRNA using Lipofectamine 2000, 
as described above. After incubation in growth conditions in full culture medium for $48 \mathrm{~h}$, cells were trypsinized and washed with $500 \mu \mathrm{L}$ PBS. A fluorescein isothiocyanate (FITC)-labeled anti-survivin monoclonal antibody (R\&D Systems, Minneapolis, Minnesota, USA) was used to label the target protein according to the procedure recommended by the manufacturer. Survivin knockdown efficiency was quantified by measuring the decrease in mean FITC fluorescence by flow cytometry.

To measure adeno-associated virus transduction efficiency, sonicated adeno-associated virus samples were incubated with HT-1080 fibrosarcoma cells (29). Briefly, a $375-\mu \mathrm{L}$ sample of sonicated adeno-associated virus and $625 \mu \mathrm{L}$ DMEM medium supplemented with $2 \%$ FBS were added to HT-1080 cells previously incubated for 1 day in six-well plates. After incubation at $37^{\circ} \mathrm{C}$ for 1 to $2 \mathrm{~h}, 1 \mathrm{~mL}$ pre-warmed DMEM medium supplemented with $18 \%$ FBS was added per well. Cells were then incubated and analyzed by flow cytometry, as described above. Transduction efficiency was measured by determining the percentage of cells with green fluorescence due to GFP expression greater than untreated control cells.

To measure cell viability, propidium iodide (Molecular Probes, Eugene, Oregon, USA) was added to sonicated rat cortical neurons at a concentration of 1 vol. \% $5 \mathrm{~min}$ after sonication. Cell viability was measured by determining the percentage of cells lacking red fluorescence due to propidium iodide staining compared to untreated control cells (28).

\section{Statistical Analysis}

Analysis of variance and Student's $t$ test were applied to the data. A value of $p<0.05$ was interpreted as significant. All data are reported as the mean \pm the standard deviation.

\section{RESULTS}

This study was designed to broadly assess the ability of US to enhance transport and distribution of drugs in the brain. More specifically, we tested: (a) to enhance transport of large molecules across brain tissue in vitro, (b) to validate in vitro findings by examining the effect of US on transport in the monkey brain in vivo, and (c) to validate that the US conditions used in this study do not damage brain tissue or the therapeutic molecules being delivered to the brain.

\section{In vitro Brain Delivery}

Relationship between sonication parameters and tissue permeability. We first tested the general hypothesis that US increases the permeation of molecules across brain tissue. In support of this hypothesis, Fig. 3a shows that US significantly enhanced mannitol transport across porcine brain tissue in vitro $(p<0.05$ for all US settings compared to control). Consistent with previous ultrasonic drug delivery studies in other tissues (23), mannitol transport enhancement shows a good correlation with ultrasonic energy density for each frequency (Fig. 3a). The various energy densities were achieved by applying US at different pressures and different duty cycles at a constant exposure time of $4 \mathrm{~h}$. Additional statistical analysis showed that permeability enhancement also increased with increasing pressure and increasing duty cycle $(p<0.05)$. The highest enhancement of 24-fold was observed at an energy density of $\sim 1,200 \mathrm{~J} / \mathrm{cm}^{2}$ at a frequency of $85 \mathrm{kHz}$. At a given energy density, the enhancement decreased with increasing frequency $(p<0.05)$. The enhancement of mannitol transport at a constant energy density $\left(1,500 \mathrm{~J} / \mathrm{cm}^{2}\right)$ for three frequencies is shown in Fig. $3 \mathrm{~b}$.
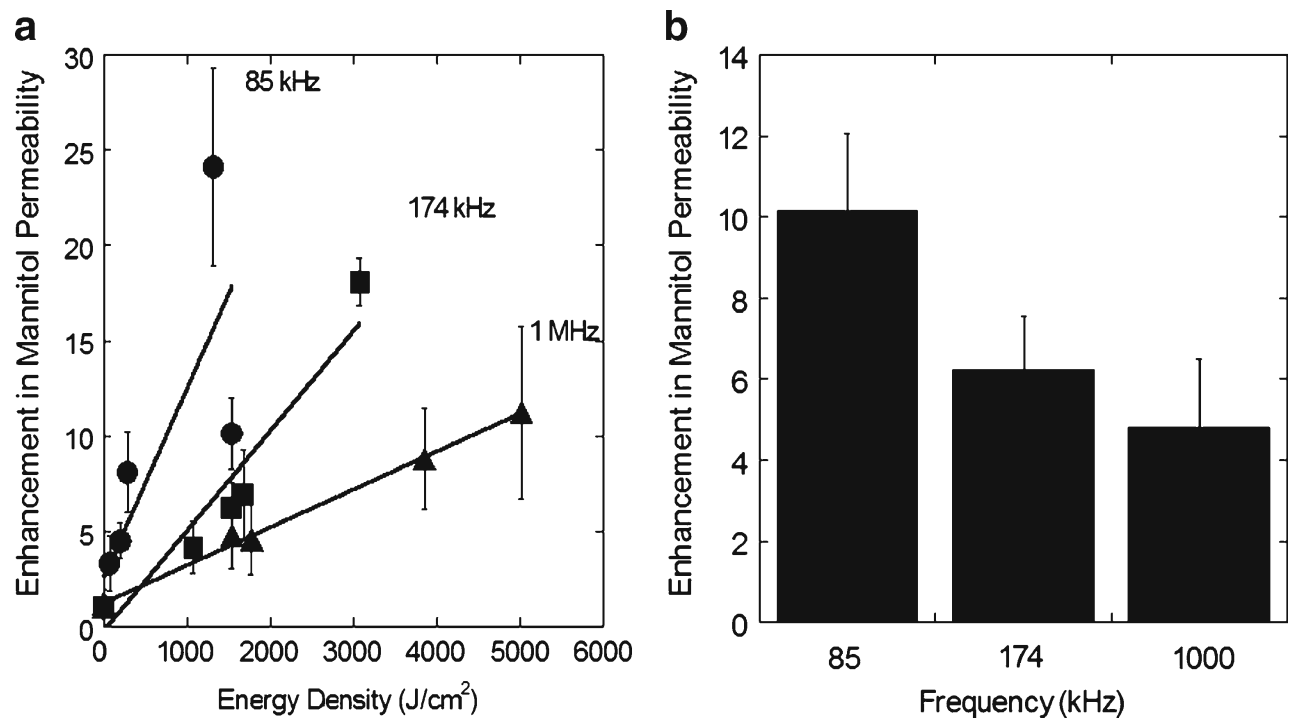

Fig. 3. In vitro brain slice permeability enhancement at different US conditions. a Variation of normal porcine brain tissue permeability enhancement as a function of the energy density of the transducer at three different US frequencies- $85 \mathrm{kHz}$ (circle), $174 \mathrm{kHz}$ (square), $1 \mathrm{MHz}$ (triangle). The lines show linear regressions of the data $\left(r^{2}=0.99(1 \mathrm{MHz}), 0.96(174 \mathrm{kHz}), 0.80(85 \mathrm{kHz}), n=3\right.$ replicates $)$. All data points are significantly different from the non-sonicated control $(p<0.05)$. b Variation of the permeability enhancement as a function of US frequency at a constant energy density $\left(1,500 \mathrm{~J} / \mathrm{cm}^{2}\right)$. Data are taken from a. Each of the data points is significantly different from each other $(p<0.05)$. Enhancement values are determined relative to permeability of non-sonicated tissue 
An enhancement of 10.14-fold in mannitol transport was observed at $85 \mathrm{kHz}$, which decreased to 4.87 -fold at $1-\mathrm{MHz}$ US exposure.

Relationship between electrical conductivity and permeability. US can increase permeation across brain tissue by acting on the molecule to provide a driving force for transport and by acting on the tissue to increase its permeability. To assess the role of the latter component, we measured brain tissue conductivity during sonication, which is a measure of tissue permeability and should not be influenced by US effects on the molecule. This analysis showed that enhancement in mannitol transport was accompanied by an increase in electrical conductivity of the brain tissue. In the absence of US, the tissue possessed a very low electrical conductance $\left(0.45 \times 10^{-4}-1.12 \times\right.$ $10^{-4} \mathrm{~S} / \mathrm{m}$ ) which, upon sonication, increased quickly and plateaued after about $2 \mathrm{~h}\left(1.97 \times 10^{-3}-2.36 \times 10^{-3} \mathrm{~S} / \mathrm{m}\right)$. Electrical conductivity enhancement, measured relative to the controls at the end of the $4 \mathrm{~h}$ sonication period, correlated well with the corresponding mannitol permeability enhancement (Fig. 4, $r=0.94$ for linear fit). This linear relationship between permeability enhancement and conductivity enhancement was true for all of the frequencies and energy densities reported in this study, which suggests an important role for US effects on the tissue to increase its permeability.

Transport across brain tumors. For possible applications to treat brain cancer, we exposed human brain 9-L tumor tissue explanted from rats to $1-\mathrm{MHz}$ US at an energy density of $5,000 \mathrm{~J} / \mathrm{cm}^{2}$. Under these conditions, the passive permeability $\left(7.20 \pm 0.63 \times 10^{-5} \mathrm{~cm} / \mathrm{min}\right)$ of the tumor-bearing tissue was increased by approximately 2.5 -fold to a final permeability of $1.82 \pm 0.19 \times 10^{-4} \mathrm{~cm} / \mathrm{min}$ at the end of the $4-\mathrm{h}$ sonication ( $p=0.03$; Fig. 5$)$.

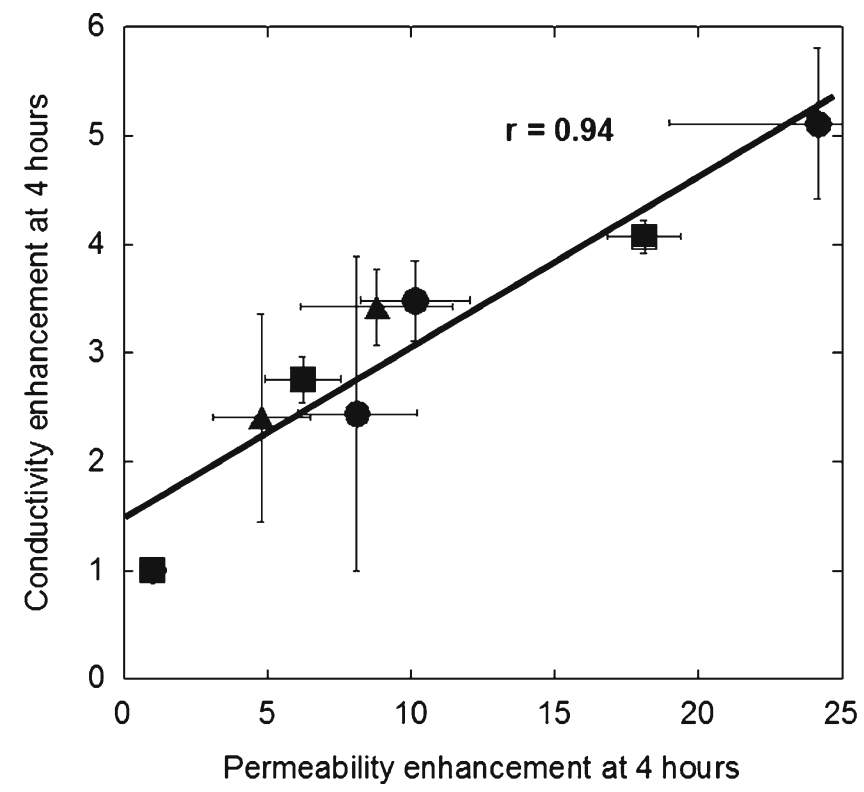

Fig. 4. In vitro electrical conductivity enhancement plotted against transport permeability enhancement for normal porcine brain tissue under the influence of US (Pearson's product-moment correlation coefficient, $r=0.94$ for linear fit) at $85 \mathrm{kHz}$ (circle), $174 \mathrm{kHz}$ (square), and $1 \mathrm{MHz}$ (triangle). Permeability data were taken from Fig. $2 \mathrm{a}(n \geq$ 3 replicates)

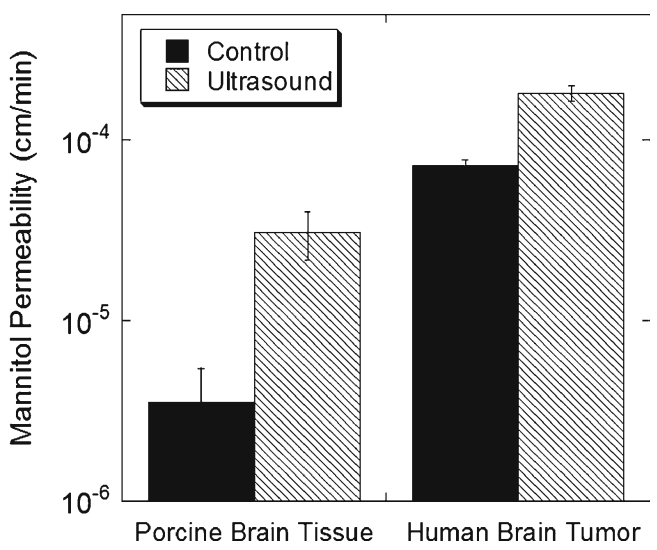

Fig. 5. Mannitol permeability values in normal porcine brain tissue and human brain 9-L flank tumor tissue with and without US exposure. The tissues were exposed for $4 \mathrm{~h}$ to $1-\mathrm{MHz}$ US at $5 \%$ duty cycle and a total energy density of $5,000 \mathrm{~J} / \mathrm{cm}^{2}$ ( $n=3$ replicates): US increased tissue permeability in normal porcine brain tissue $(p=0.016)$ and in human brain tumor tissue $(p=0.03)$

Dependence of permeability on molecular weight. Because different brain therapies may require drugs and biotherapeutics of different sizes, the dependence of brain tissue permeability on molecular weight was tested using four hydrophilic solutes: water (18 Da), mannitol (180 Da), inulin (5 kDa), and dextran (70 kDa; Fig. 6a). In the absence of US, brain permeability exhibited a strong size selectivity $(p<0.05)$. Permeability decreased by about 44-fold as the molecular weight of the solute increased from $18 \mathrm{Da}$ (water) to $70 \mathrm{kDa}$ (dextran). Water had a much larger permeability $\left(8.42 \times 10^{-5} \mathrm{~cm} / \mathrm{min}\right)$, whereas the three larger solutes had similar permeabilities $\left(\sim 2 \times 10^{-6} \mathrm{~cm} / \mathrm{min}\right)$. Upon application of US, tissue permeability to all four molecules increased by 2.3 - to 8.8 -fold $(p<0.05)$, and the permeabilities of each molecule were statistically different from each other $(p<0.05)$. Similar to passive permeabilities, ultrasonic permeability decreased by about 43 -fold as the solute molecular weight increased from $18 \mathrm{Da}$ (water) to $70 \mathrm{kDa}$ (dextran).

We also examined brain tissue permeability to a lipophilic drug-BCNU, which is used to treat brain cancer. BCNU (MW $\sim 214 \mathrm{Da}$ ) exhibited a passive permeability of $1.90 \pm 0.90 \times 10^{-6}$ $\mathrm{cm} / \mathrm{min}$ in porcine brain tissue (Fig. 6b), which was statistically indistinguishable from a hydrophilic molecule of similar size (mannitol, $180 \mathrm{Da}, 3.51 \pm 1.97 \times 10^{-6} \mathrm{~cm} / \mathrm{min} ; p<0.05$ ). US enhanced brain permeability to BCNU by 2.8 -fold to $5.80 \pm$ $1.24 \times 10^{-6} \mathrm{~cm} / \mathrm{min}(p=0.007)$. BCNU permeability enhancement was significantly less than mannitol enhancement $(p=0.016)$. Although BCNU and mannitol are of similar molecular weight, higher lipophilicity of $\mathrm{BCNU}(\log P=1.5)$ than mannitol $(\log P=-3.1)$ suggests that transport pathways opened up by sonication are aqueous in nature and thereby preferentially enhance transport of hydrophobic molecules.

Histology. As a preliminary test of safety, histological examination confirmed that a moderate exposure to US $\left(85 \mathrm{kHz}, 174 \mathrm{kHz}\right.$, and $\left.1 \mathrm{MHz} ; 1,250 \mathrm{~J} / \mathrm{cm}^{2}\right)$ did not induce physical structural changes at the microscopic scale in the non-viable porcine brain tissue. All brain sections (control and treated) appeared intact with minimal cellular distortions (data not shown). There were no differences between the 
a

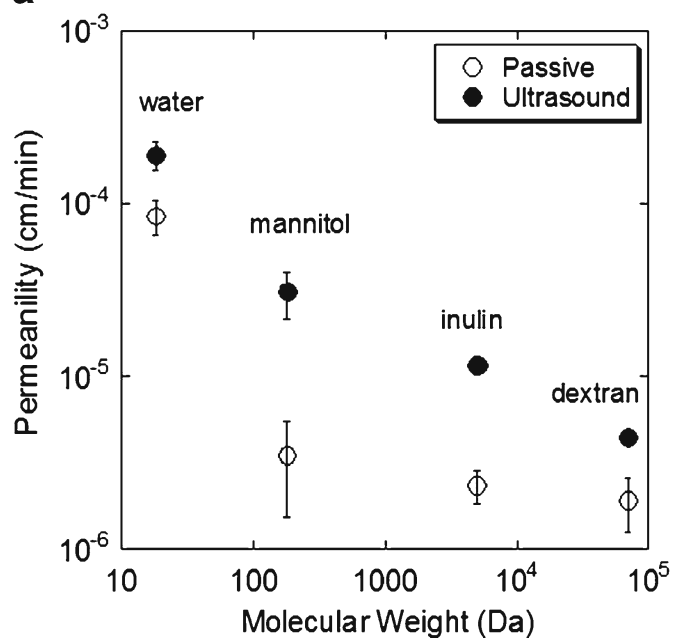

b

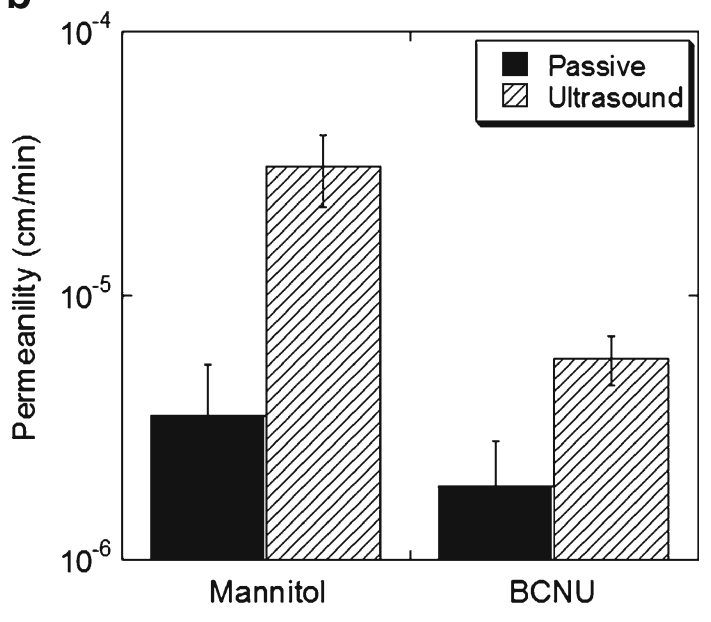

Fig. 6. In vitro brain slice permeability to different molecules. a Variation of normal porcine brain tissue permeability as a function of the molecular weight of the molecule being transported under passive (empty circle) and sonicated (filled circle) conditions. Sonication was carried out at $1 \mathrm{MHz}, 5 \%$ duty cycle for $4 \mathrm{~h}$ at a total energy density of $5,000 \mathrm{~J} / \mathrm{cm}^{2}$ ( $n=3$ replicates). For each molecule, permeability during sonication was greater than under passive conditions $(p \leq 0.05)$. b Dependence of permeability to mannitol and BCNU under passive (black bar) and sonicated (striped bar) conditions. Sonication was carried out at the same conditions as in $\mathbf{a}$ ( $n=3$ replicates). Permeability was greater during sonication compared to passive conditions for mannitol $(p=0.016)$ and $\mathrm{BCNU}(p=0.007)$

controls and the treated samples in regards to the cellular structure and tissue integrity as observed by light microscopy.

\section{In Vivo Brain Delivery}

Effects of US on liposomal distribution. Based on these in vitro findings, we next studied the ability of US to increase transport in brain tissue in vivo using a cynomolgus monkey model. Although lower-frequency US increased tissue permeability to a greater extent in vitro, we chose to use higher-frequency (i.e., $1 \mathrm{MHz}$ ) US for the in vivo study to reduce the likelihood of cavitation, which is suppressed at higher frequency, and to enable better spatial localization of effects, which is enhanced at higher frequency. In this study, gd-lipo were infused into the corona radiate using separate cannulas on the left and right hemispheres of the brain, and at specific times, $1-\mathrm{MHz}$ US was applied at the site of infusion on the left hemisphere. Distribution of the gd-lipo was monitored over time by MRI. This in vivo study administered gd-lipo to facilitate MRI imaging, even though gd-lipo are much bigger than molecules examined in the in vitro studies. Three trials were conducted sequentially on the same cynomolgus monkey. Figure 7 contains representative data showing how gd-lipo distribution volumes were determined in the brain. Figure 7a displays an MRI series from the posterior to the anterior brain, in which US was applied to the left hemisphere. The bright white regions are areas containing gd-lipo. Through computer image analysis, the edges of the white regions were identified and stacked on top of each other, as shown in Fig. 7b. A quasi-threedimensional representation is also shown in Fig. 7c. The volume of these stacked images corresponded to the gd-lipo volume of distribution, and the data were listed in Table I. Significant effect of US on gd-lipo distribution was observed in trial II and trial III, but not trial I. The volume of distribution increased by $121 \%$ in trial II and $54 \%$ in trial III after three US sessions, which was much larger than the nonsonicated control ( $48 \%$ in trial II and $36 \%$ in trial III).

Closer examination of coronal MR images acquired after trial III revealed that the gd-lipo distribution beneath the US device appeared flatter and extended 2 to $3 \mathrm{~mm}$ further in the anterior-posterior direction when compared to the nonsonicated hemisphere. In addition, distribution of the gd-lipo in the anterior-posterior direction beneath the US device was enhanced from $9 \mathrm{~mm}$ (right) to $12 \mathrm{~mm}$ (left). The extent of enhanced delivery as a result from US administration was consistent with the second trial, which also showed a marked difference in liposomal distribution when compared to delivery without sonication.

Clinical assessments. Clinical assessments were performed on a daily basis to evaluate changes in animal behavior and monitor clinical signs following the first US trials. The animal tolerated the US procedure with no motor deficits or signs of adverse effects, although a transient decrease in appetite was observed on the morning after the US procedure that persisted over a 5-day period.

Necropsy and histology. Gross necropsy findings after the completion of all three trials revealed evidence of infection on the surface of the dura within proximity to each cannula entry site, including minor infection at the site of the invasive procedure. Coronal examination of each brain slice showed evidence of liposomal rhodamine infusion into cortical and subcortical areas proximal to the cannula site. Evaluation of liposomal rhodamine distribution was consistent with gadolinium MRI findings. Further qualitative microscopic evaluation showed that liposomal rhodamine uptake in the US-treated hemisphere was homogeneously dispersed over a wide region at the cannulated site (Fig. 7d). All normal 
a
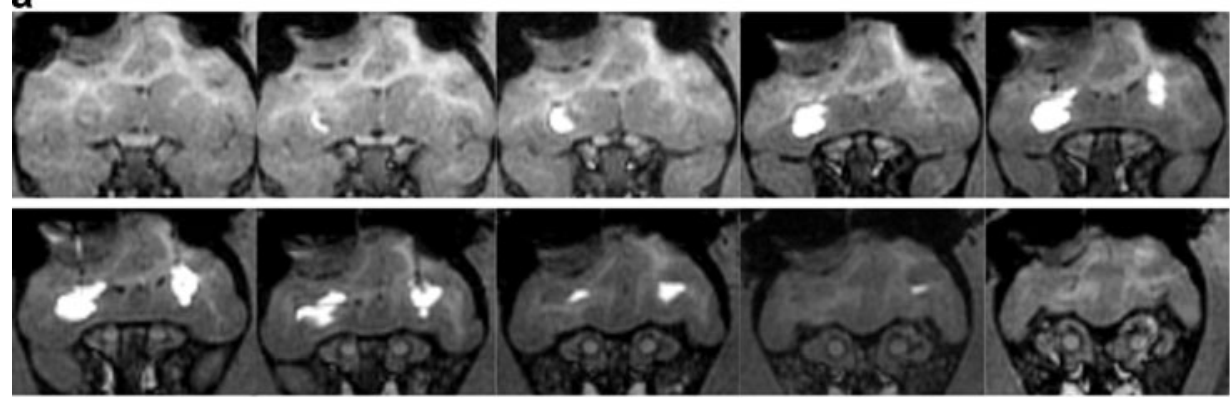

b

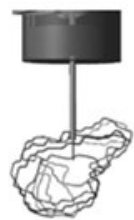

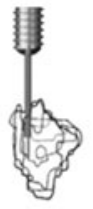

c

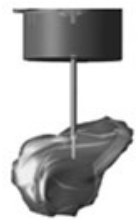

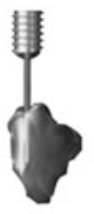

d

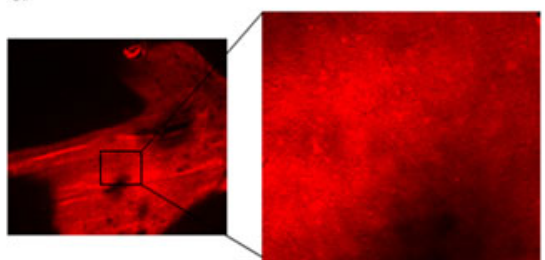

Fig. 7. Distribution of liposome in the non-human primate brain. a Illustrative MRI series (parallel coronal slices, from the upper left to the lower right, posterior to anterior) showing gd-lipo distribution after the third US session in trial II. The presence of gd-lipo is indicated by white coloring in the left sonicated hemisphere and the right non-sonicated hemisphere. b, c Graphical superposition of the areas of gd-lipo distribution to create a quasi-three-dimensional image of the volume of gd-lipo distribution. d Low and high magnification of a representative histology slide from the left hemisphere (US treated) showing rhodamine-loaded liposome infusion within and between the neuronal cells

neuronal cells, the necrotic tissues and the infiltrating inflammatory cells within the affected zone, demonstrated uniform staining characteristics. The tissue immediately adjacent and beyond the rhodamine positive were normal and devoid of fluorescence. In comparison, the non-sonicated site demonstrated similar rhodamine fluorescence but within narrow confines of the cannula tract. However, the staining intensity was comparable to the treated region.

\section{In Vitro Safety and Drug Bioactivity}

To evaluate the possibility that US exposure can adversely affect the integrity and, therefore, the bioactivity of various therapeutic agents, we carried out studies to examine the effects of US on the integrity of plasmid DNA, siRNA, and a viral vector. We selected these models because they are of interest to gene-based therapies and might be more sensitive to damage by US compared to, for example, small molecule drugs like BCNU. Possible damage to neuronal cells, cultured in vitro, by US exposure was also examined to supplement the in vivo pre-clinical study.

To assess whether US damages DNA, we exposed plasmid DNA encoding GFP to US over energy densities ranging from 0 to $12,000 \mathrm{~J} / \mathrm{cm}^{2}$. We selected this range of US conditions because it included and well exceeded those found to be useful for enhanced delivery in vitro and in vivo in the previous sections. After sonication, the DNA was transfected into cultured cells using a lipid transfection agent as an assessment of DNA integrity. There was no significant difference in transfection efficiency between DNA sonicated at any of the conditions tested compared to non-sonicated controls $(p>0.05)$ as shown in Fig. 8a. Note that sonication was not used in this study to aid, for example, DNA entry into cells, as has been reported before (30). The goal of this safety study was to determine if sonication damaged DNA in some way that affected subsequent transfection of cells.

A similar experiment was carried out to assess the effects of US on the ability of siRNA to knock down expression of a model protein, survivin. As shown in Fig. 8b, there were no significant differences in the level of protein knockdown between siRNA sonicated at any of the conditions tested compared to non-sonicated controls $(p>0.05)$.

The effects of US on function of an adeno-associated virus are shown in Fig. 8c. Over the range of conditions examined, there were no significant differences in the level of transduction efficiency between sonicated adeno-associated virus and non-sonicated controls $(p>0.05)$, indicating the integrity of virus was not affected by US.

Finally, the effect of US on the viability of cortical neurons freshly harvested from fetal rats was examined. As shown in Fig. 8d, sonication at pressures up to $1.5 \mathrm{MPa}$ for up to $60 \mathrm{~min}$ (energy density $6,750 \mathrm{~J} / \mathrm{cm}^{2}$ ) had no significant effect on neuronal cell viability $(p>0.05)$, which is consistent with the previous histology study. However, cell viability was decreased when the acoustic pressure was increased to the highest energy density of $12,000 \mathrm{~J} / \mathrm{cm}^{2}$, which caused cell viability to decrease by $19 \% \quad(p=0.0013)$. As a positive control, sonication was carried out at $2,000 \mathrm{~J} / \mathrm{cm}^{2}$ in the presence of Definity ${ }^{\circledR}$ US contrast agent, which served to nucleate cavitation activity. Under these conditions, cell viability was reduced by $35 \%(p=0.0006)$. However, the conditions that caused losses of cell viability are much stronger than the ones found to be useful for enhanced delivery in the previous sections.

\section{DISCUSSION}

Previous studies have addressed ultrasonic drug delivery into and across various tissues (13-16) including breaching 
Table I. Distribution Volume of gd-lipo and the Volume Change in Both Hemispheres During US Exposure

\begin{tabular}{|c|c|c|c|c|}
\hline & \multicolumn{2}{|c|}{ Volume $(\mu \mathrm{L})$} & \multicolumn{2}{|c|}{ Volume change $^{a}$} \\
\hline & Left (sonicated) & Right (non-sonicated) & Left (sonicated; \%) & Right (non-sonicated; \%) \\
\hline \multicolumn{5}{|l|}{ Trial I } \\
\hline Before US sessions & 33 & 45 & & \\
\hline After 1st 30-min US session & 38 & 58 & 15 & 29 \\
\hline After 2nd 30-min US session & 95 & 146 & 188 & 224 \\
\hline After $16 \mathrm{~h}$ & 279 & 310 & & \\
\hline After 60-min US session & 254 & 235 & & \\
\hline After $10 \mathrm{~min}$ & 229 & 220 & & \\
\hline \multicolumn{5}{|l|}{ Trial II } \\
\hline Before US sessions & 82 & 65 & & \\
\hline After 1st 30-min US session & 101 & 65 & 23 & 0 \\
\hline After 2nd 30-min US session & 114 & 84 & 39 & 29 \\
\hline $\begin{array}{l}\text { After } 200-\text { min "rest" session and } \\
\text { additional } 20-\mu \mathrm{L} \text { infusion }\end{array}$ & 158 & 91 & 93 & 40 \\
\hline After 3rd 60-min US session & 181 & 96 & 121 & 48 \\
\hline After $16 \mathrm{~h}$ & 119 & 82 & & \\
\hline After 60 -min US session & 124 & 60 & & \\
\hline \multicolumn{5}{|l|}{ Trial III } \\
\hline Before US sessions & 241 & 269 & & \\
\hline After 1st 60-min US session & 328 & 295 & 36 & 10 \\
\hline After 2nd 60-min US session & 364 & 341 & 51 & 27 \\
\hline After 3rd 60-min US session & 371 & 367 & 54 & 36 \\
\hline
\end{tabular}

US exposure conditions-1.24 MPa (MI=1.24), pulse length of $20 \mu$ s, duty cycle of $2.5 \%$

US ultrasound

${ }^{a}$ The volume change is calculated based on the comparison to the volume before US sessions.

the BBB to facilitate delivery of molecules across the vascular barrier into the brain $(31,32)$. In this study, using in vitro and in vivo analysis, we provide a detailed assessment of the ability of US to further enhance drug transport and distribution in the brain from a macroscopic tissue-level perspective. We quantify bulk transport of drugs in the brain tissue by placing an US transducer directly in contact with the tissue to enhance localized tissue permeability. In the in vitro experiments, a significant increase in drug transport across brain tissue was found to occur over a broad range of US conditions; however, the degree of transport enhancement achieved was strongly dependent on US parameters. The enhancement increased proportionally with the energy density and inversely with the frequency. Such dependencies are consistent with previous observations on ultrasonic drug delivery to cells and tissues other than the brain $(16,33)$. In particular, the inverse dependence of drug permeability on frequency suggests the role of US-induced acoustic cavitation in transport enhancement. The primary effect of US waves is to physically perturb the material medium of passage, causing the exposed material to vibrate at an amplitude dependent on the material's compressibility. For densely packed materials such as brain tissue, US is expected to produce low displacement, but for compressible gas bubbles or cavities in the unconstrained saline bathing the brain tissue in vitro, US may result in high displacements and strains yielding to cavitation. This suggests that within the in vivo brain, where there is no saline bath, cavitation should occur to a lesser extent. Because the induction of cavitation is associated with increased risk of mechanical damage to brain tissue, higher ultrasound frequency exposure $(1 \mathrm{MHz})$ was preferred in the in vivo experiments of this study to further minimize this risk.
In principle, ultrasound may increase drug transport across brain tissue by exerting convective forces on drugs or by increasing the permeability of the brain tissue itself. Since electrical conductivity, a measure of tissue permeability, correlated well with drug transport, it suggests that US chiefly affects the brain tissue and thus its permeability to drugs. Upon US treatment, the magnitude of increase in brain tissue conductivity ( $\sim 10$ - to 50 -fold) was similar to the increase in mannitol tissue permeability (up to $\sim 25$-fold). Consistently, the relationship between mannitol transport enhancement and electrical conductivity enhancement was independent of the ultrasonic frequency and energy density, suggesting a lesser role of ultrasonic convective forces. Solute permeability across the brain tissue decreased with increasing solute size. The presence of a strong size dependence also suggests that solute transport during US application may be mediated by diffusion as opposed to convection.

US at $1 \mathrm{MHz}$ also enhanced mannitol transport across human brain tumor tissue excised from the rat flank. Passive permeability of the tumor tissue was about 20-fold higher than that of the normal tissue. High tissue permeability correlates well with increased diffusivity of solutes in the tissue interstitium, which is consistent with several literature reports documenting increased drug diffusivity in tumors (34). The tumor interstitial compartment is characterized by large interstitial space, high collagen concentration, low proteoglycan, and hyaluronate concentrations leading to a high interstitial diffusion coefficient for a variety macromoleculesup to an order of magnitude higher compared to normal tissues (34,35). As such, US exposure can increase brain tissue permeability by potentially expanding the tissue interstitium. Ultrastructural studies have reported on US- 
a

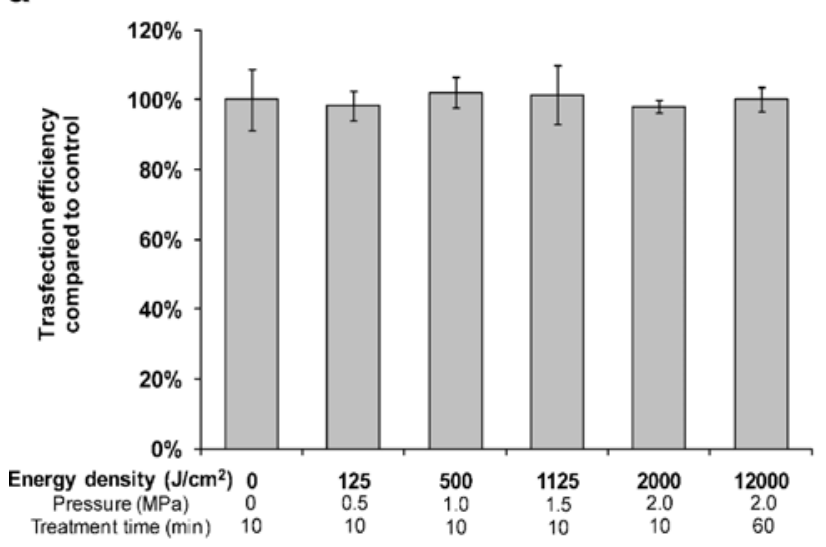

b

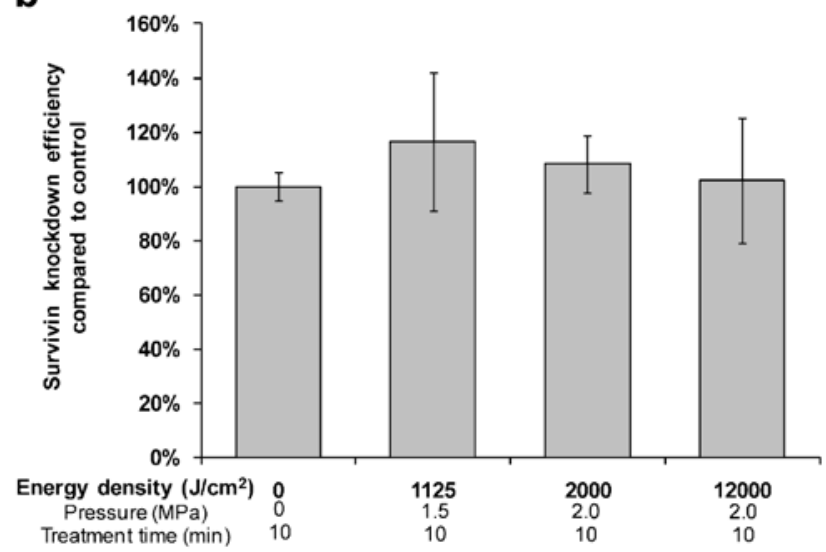

C

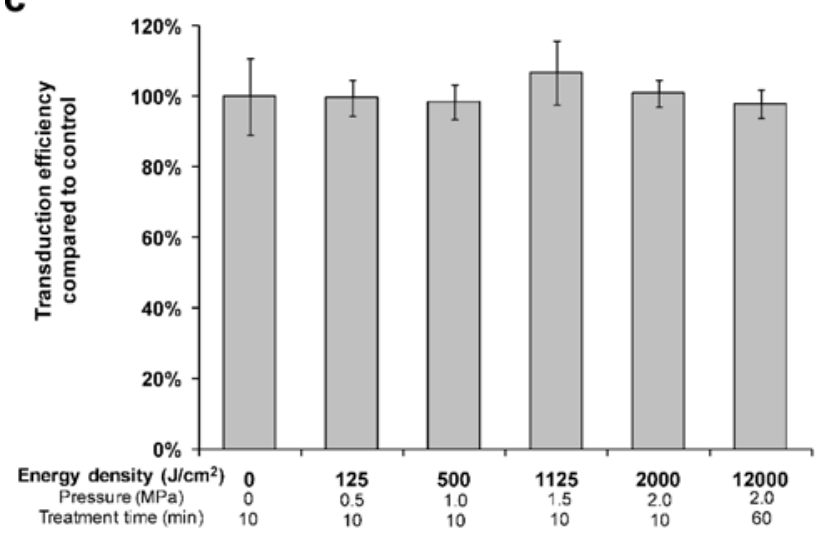

d

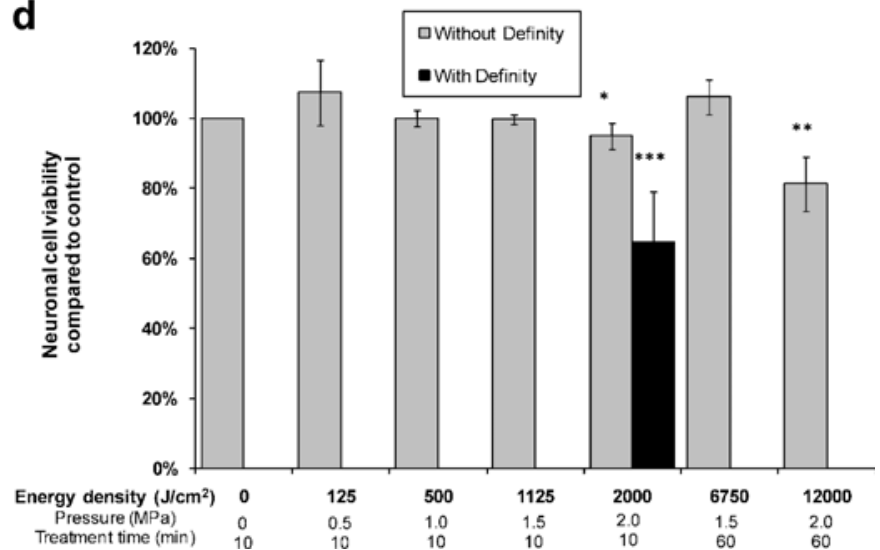

Fig. 8. Effect of US exposure on plasmid DNA, siRNA, virus integrity, and cortical neuron viability. a Plasmid gWizTM-GFP and b survivinsiRNA were sonicated and subsequently transfected to DU145 cells by Lipofectamine 2000. Each bar displays the average and standard deviation of $\mathbf{a}$ the transfection efficiency normalized by the non-sonicated control DNA and $\mathbf{b}$ the survivin knockdown efficiency normalized by the non-sonicated siRNA ( $n \geq 4$ replicates). Percent survivin knockdown was determined based on survivin expression levels from cells without siRNA transfection set equal to $0 \%$ protein knockdown. Student's $t$ test showed no significant changes in a transfection efficiency and b knockdown efficiency at any of the conditions tested relative to the non-sonicated control $(p>0.05)$. c Adeno-associated virus was sonicated and subsequently transduced to HT-1080 cells. Each bar displays the average and standard deviation of the transduction efficiency normalized by non-sonicated control virus ( $n \geq 4$ replicates). Student's $t$ test showed no significant changes in transduction efficiency at any of the conditions tested relative to the non-sonicated control $(p>0.05)$. d Cortical neurons were sonicated at different US conditions and, in one case, in the presence of Definity ${ }^{\circledR}$ US contrast agent. Each bar displays the average and standard deviation of the cell viability normalized by non-sonicated control neurons ( $n \geq 4$ replicates). Student's $t$ test showed no significant changes in cell viability at any of the conditions tested relative to the non-sonicated control $(p>0.05)$, except at the conditions indicated: ${ }^{*} p=0.016, * * p=0.0013, * * * p=0.0006$

induced cavitation forces to either create extracellular spaces or dilate interstitium in tissues other than brain $(36,37)$. Our limited histological analysis did not reveal any structural changes in the brain tissue treated with US; however, additional studies are needed to assess the brain ultrastructure (at the nanometer length scale using electron microscopy) to probe this hypothesis.

In addition to increasing transport of a number of model compounds, US was shown to increase delivery of BCNU across brain tissue. $\mathrm{BCNU}$ is a leading chemotherapeutic drug used for the treatment of brain tumors (38). Its efficacy is believed to be limited in part by its poor transport and distribution in the brain (39). The intracranial spatial distribution of BCNU during chemotherapy is determined by a complex interplay of a host of known and unknown mechanisms including diffusion, convection, and permeation through the vascular endothelium (40). Various experimental and theoretical studies have shown that BCNU exhibits limited penetration when delivered from an implanted depot in the brain $(41,42)$. The small penetration depths are thought to originate from rapid clearance of $\mathrm{BCNU}$ into systemic circulation owing to its high transvascular permeability. This diffusion-elimination related drop in concentration cannot be easily compensated for by increasing the BCNU concentrations in the depot because of toxicity to the surrounding healthy tissue. Accordingly, mechanisms to facilitate the distribution of BCNU more evenly throughout the tissue surrounding the primary tumor may improve therapeutic effectiveness of the drug. Our results demonstrate that US can be potentially used for this purpose.

Increased brain tissue permeability may result due to perturbation of various anatomical barriers within the brain 
tissue including the blood-brain barrier (43). In vitro experiments were performed with excised brain tissue and may be lacking in structural barriers that are only functional in a living brain. Therefore, we carried out additional experiments in a non-human primate in vivo. To facilitate high-resolution non-invasive MRI imaging, gadolinium-encapsulated liposomes were used as a large model therapeutic that transports poorly in the brain and would benefit from increased transport using US. This study showed that the distribution volume of the liposomes could be increased by US. This result was consistent with in vitro results and with our hypothesis that US can enhance transport within the brain in vivo. Although the limited availability and cost of non-human primate studies permitted us to provide in vivo data from only a few experiments that each used somewhat different conditions, future studies should be aimed at optimizing the US parameters to build off these preliminary results.

This study also provided an initial assessment of the safety of US exposure. Because of its non-invasive nature, US has the potential to avoid tissue damage. This safety, under other US conditions, is well established for clinical use of US for diagnostic imaging and therapeutic heating (44). Histological examination of the in vitro brain tissues exposed to US did not show gross tissue damage at any of the conditions studied. Experiments in a non-human primate similarly found no indications of damage from US. Although a transient decrease in appetite was observed, no changes in animal vital signs and animal health were observed during and after sonication. Energy density of $1,250 \mathrm{~J} / \mathrm{cm}^{2}$ was chosen to correspond to the maximum brain permeability enhancement (24-fold at $85 \mathrm{kHz}$ ) observed in the in vitro study (Fig. 3). As such, safety threshold for various mechanical bioeffects of US has been reported to correlate well with the MI of ultrasonic exposure. US exposure with $\mathrm{MI}<1.9$ is generally regarded safe in tissues other than the eye (45). Consistently, in the present study, histological analysis of ultrasonic exposure at MI between 0.40 to 1.37 in vitro and $\mathrm{MI}=1.24$ in vivo revealed no gross damage to the brain tissue. Exposure of US was found to be well tolerated by cultured cortical neurons in vitro. Specifically, viability of cortical neurons was unaffected over most conditions. Sonication at the highest energy density of $12,000 \mathrm{~J} / \mathrm{cm}^{2}$ significantly reduced cell viability; however, this energy level was well beyond the conditions found to be effective for enhanced delivery.

As a secondary objective, we evaluated the potency of US brain delivery not only to facilitate drug delivery into the brain but also to preserve the biological activity of the drugs delivered by it. The sonochemical effects of US such as production of free radicals during cavitation events have been demonstrated to change the activity of drugs (46). We carried out experiments designed to assess the functionality of several therapeutic biomolecules of interest after US treatment. This study showed that exposure to US at any of the conditions tested did not significantly affect transfection efficiency of the plasmid DNA, protein knockdown efficiency of the siRNA, or transduction efficiency of the adeno-associated virus. These studies suggest that there is a broad range of US conditions that may be suitable for enhanced delivery to the brain without damaging the integrity of plasmid DNA, siRNA, adeno-associated virus, or cortical neurons. Additional in vivo studies will be needed, which eliminate the artifacts of in vitro cells in suspension, such as increased shear stress due to acoustic streaming and cavitational activity, and the inability of cell culture models to fully mimic brain tissue in vivo. Other studies, using different US conditions for different, but related, applications in the brain, have also assessed US safety (32).

\section{CONCLUSIONS}

The study demonstrates that US is capable of enhancing the permeation of several molecules including BCNU through brain tissue in vitro and increasing the distribution volume of liposomes in the non-human primate brain in vivo. Enhanced delivery can be achieved at conditions that did not appear to damage the integrity of DNA, siRNA, adenoassociated virus, cortical neurons, or tissues. Altogether, these findings suggest that US may provide a useful tool to enhance delivery of therapeutics in the brain.

\section{ACKNOWLEDGMENTS}

We thank Dr. Henry Brem at the Johns Hopkins University, for providing frozen brain tissues, Dr. Kacy Cullen and Dr. Michelle LaPlaca at the Georgia Institute of Technology for providing cortical neurons, and Dr. Heather Bara and Dr. Thanassios Sambanis at the Georgia Institute of Technology for providing adeno-associated virus. This work was supported primarily by CytoDome, Inc., as well as the Georgia Research Alliance, and the National Institutes of Health. Gd-lipo were kindly provided by Hermes Biosciences Inc. Dr. Sumit Paliwal and Dr. Samir Mitragotri carried out the in vitro tissue permeability studies. Dr. Krys Bankiewicz and John Bringas carried out the in vivo non-human primate study, and Dr. Gill Heart carried out its quantitative analysis. Ying Liu and Dr. Mark Prausnitz carried out the in vitro bioactivity study. Ying Liu and Dr. Sumit Paliwal primarily wrote the manuscript.

Open Access This article is distributed under the terms of the Creative Commons Attribution Noncommercial License which permits any noncommercial use, distribution, and reproduction in any medium, provided the original author(s) and source are credited.

\section{REFERENCES}

1. Lesniak MS, Brem H. Targeted therapy for brain tumours. Nat Rev Drug Discov. 2004;3(6):499-508.

2. Boiardi A, Eoli M, Pozzi A, Salmaggi A, Broggi G, Silvani A. Locally delivered chemotherapy and repeated surgery can improve survival in glioblastoma patients. Ital J Neurol Sci. 1999;20(1):43-8.

3. Giussani C, Carrabba G, Pluderi M, Lucini V, Pannacci M, Caronzolo $\mathrm{D}$, et al. Local intracerebral delivery of endogenous inhibitors by osmotic minipumps effectively suppresses glioma growth in vivo. Cancer Res. 2003;63(10):2499-505.

4. Brem H, Mahaley Jr MS, Vick NA, Black KL, Schold Jr SC, Burger PC, et al. Interstitial chemotherapy with drug polymer implants for the treatment of recurrent gliomas. J Neurosurg. 1991;74(3):441-6.

5. Langer R, Brem H, Falterman K, Klein M, Folkman J. Isolation of a cartilage factor that inhibits tumor neovascularization. Science. 1976;193(4247):70-2. 
6. Mak M, Fung L, Strasser JF, Saltzman WM. Distribution of drugs following controlled delivery to the brain interstitium. J Neurooncol. 1995;26(2):91-102.

7. Storm PB, Moriarity JL, Tyler B, Burger PC, Brem H, Weingart J. Polymer delivery of camptothecin against $9 \mathrm{~L}$ gliosarcoma: release, distribution, and efficacy. J Neurooncol. 2002;56(3):209-17.

8. Saltzman WM, Mak MW, Mahoney MJ, Duenas ET, Cleland JL. Intracranial delivery of recombinant nerve growth factor: release kinetics and protein distribution for three delivery systems. Pharm Res. 1999;16(2):232-40.

9. Kunwar S. Convection enhanced delivery of IL13-PE38QQR for treatment of recurrent malignant glioma: presentation of interim findings from ongoing phase 1 studies. Acta Neurochir Suppl. 2003;88:105-11.

10. Lidar Z, Mardor Y, Jonas T, Pfeffer R, Faibel M, Nass D, et al. Convection-enhanced delivery of paclitaxel for the treatment of recurrent malignant glioma: a phase I/II clinical study. J Neurosurg. 2004;100(3):472-9.

11. Mardor Y, Roth Y, Lidar Z, Jonas T, Pfeffer R, Maier SE, et al. Monitoring response to convection-enhanced taxol delivery in brain tumor patients using diffusion-weighted magnetic resonance imaging. Cancer Res. 2001;61(13):4971-3.

12. Paliwal S, Mitragotri S. Ultrasound-induced cavitation: applications in drug and gene delivery. Expert Opin Drug Deliv. 2006;3 (6):713-26.

13. Mitragotri S, Blankschtein D, Langer R. Ultrasound-mediated transdermal protein delivery. Science. 1995;269(5225):850-3.

14. Mitragotri S, Blankschtein D, Langer R. Transdermal drug delivery using low-frequency sonophoresis. Pharm Res. 1996;13:411-20.

15. Koike H, Tomita N, Azuma H, Taniyama Y, Yamasaki K, Kunugiza Y, et al. An efficient gene transfer method mediated by ultrasound and microbubbles into the kidney. J Gene Med. 2005;7(1):108-16.

16. Shohet RV, Chen S, Zhou YT, Wang Z, Meidell RS, Unger RH, et al. Echocardiographic destruction of albumin microbubbles directs gene delivery to the myocardium. Circulation. 2000;101 (22):2554-6.

17. Alexandrov AV. Ultrasound enhancement of fibrinolysis. Stroke. 2009;40(3_suppl_1):S107-10.

18. Hynynen K, McDannold N, Vykhodtseva N, Jolesz FA. Noninvasive MR imaging-guided focal opening of the blood-brain barrier in rabbits. Radiology. 2001;220(3):640-6.

19. Hynynen K. Ultrasound for drug and gene delivery to the brain. Adv Drug Deliv Rev. 2008;60(10):1209-17.

20. Vykhodtseva N, McDannold N, Hynynen K. Progress and problems in the application of focused ultrasound for bloodbrain barrier disruption. Ultrasonics. 2008;48(4):279-96.

21. McDannold N, Vykhodtseva N, Hynynen K. Targeted disruption of the blood-brain barrier with focused ultrasound: association with cavitation activity. Phys Med Biol. 2006;51 (4):793-807.

22. Sheikov N, McDannold N, Sharma S, Hynynen K. Effect of focused ultrasound applied with an ultrasound contrast agent on the tight junctional integrity of the brain microvascular endothelium. Ultrasound Med Biol. 2008;34(7):1093-104.

23. Tezel A, Sens A, Tuchscherer J, Mitragotri S. Frequency dependence of sonophoresis. Pharm Res. 2001;18(12):1694-700.

24. Clement GT, Hynynen K. A non-invasive method for focusing ultrasound through the human skull. Phys Med Biol. 2002;47 (8):1219-36.

25. Sun J, Hynynen K. Focusing of therapeutic ultrasound through a human skull: a numerical study. J Acoust Soc Am. 1998;104(3 Pt 1): 1705-15.

26. Saito R, Krauze MT, Bringas JR, Noble C, McKnight TR, Jackson P, et al. Gadolinium-loaded liposomes allow for real-time magnetic resonance imaging of convection-enhanced delivery in the primate brain. Exp Neurol. 2005;196(2):381-9.

27. Cullen DK, LaPlaca MC. Neuronal response to high rate shear deformation depends on heterogeneity of the local strain field. J Neurotrauma. 2006;23(9):1304-19.

28. Hallow DM, Mahajan AD, McCutchen TE, Prausnitz MR. Measurement and correlation of acoustic cavitation with cellular bioeffects. Ultrasound Med Biol. 2006;32(7):1111-22.

29. Tang S-C, Sambanis A. Development of genetically engineered human intestinal cells for regulated insulin secretion using rAAV-mediated gene transfer. Biochem Biophys Res Commun. 2003;303(2):645-52.

30. Newman $\mathrm{CMH}$, Bettinger T. Gene therapy progress and prospects: ultrasound for gene transfer. Gene Ther. 2007;14 (6):465-75.

31. Patrick JT, Nolting MN, Goss SA, Dines KA, Clendenon JL, Rea MA, et al. Ultrasound and the blood-brain barrier. Adv Exp Med Biol. 1990;267:369-81.

32. Hynynen K, Clement G. Clinical applications of focused ultrasound-the brain. Int J Hyperthermia. 2007;23(2):193-202.

33. Keyhani K, Guzman HR, Parsons A, Lewis TN, Prausnitz MR. Intracellular drug delivery using low-frequency ultrasound: quantification of molecular uptake and cell viability. Pharm Res. 2001;18(11):1514-20.

34. Jain RK. Transport of molecules in the tumor interstitium: a review. Cancer Res. 1987;47(12):3039-51.

35. Jain RK. Delivery of novel therapeutic agents in tumors: physiological barriers and strategies. J Natl Cancer Inst. 1989;81 (8):570-6.

36. Lavon I, Grossman N, Kost J, Kimmel E, Enden G. Bubble growth within the skin by rectified diffusion might play a significant role in sonophoresis. J Control Release. 2007;117 (2):246-55.

37. Paliwal S, Menon GK, Mitragotri S. Low-frequency sonophoresis: ultrastructural basis for stratum corneum permeability assessed using quantum dots. J Invest Dermatol. 2006;126 (5):1095-101.

38. Kornblith PL, Walker M. Chemotherapy for malignant gliomas. J Neurosurg. 1988;68(1):1-17.

39. Blasberg RG, Patlak C, Fenstermacher JD. Intrathecal chemotherapy: brain tissue profiles after ventriculocisternal perfusion. J Pharmacol Exp Ther. 1975;195(1):73-83.

40. Fleming AB, Saltzman WM. Pharmacokinetics of the carmustine implant. Clin Pharmacokinet. 2002;41(6):403-19.

41. Fung LK, Shin M, Tyler B, Brem H, Saltzman WM. Chemotherapeutic drugs released from polymers: distribution of 1, 3-bis (2-chloroethyl)-1-nitrosourea in the rat brain. Pharm Res. 1996;13(5):671-82.

42. Wang CC, Li J, Teo CS, Lee T. The delivery of BCNU to brain tumors. J Control Release. 1999;61(1-2):21-41.

43. Hynynen K, McDannold N, Sheikov NA, Jolesz FA, Vykhodtseva N. Local and reversible blood-brain barrier disruption by noninvasive focused ultrasound at frequencies suitable for transskull sonications. Neuroimage. 2005;24(1):12-20.

44. Fowlkes JB, Holland CK. Mechanical bioeffects from diagnostic ultrasound: AIUM consensus statements. American Institute of Ultrasound in Medicine. J Ultrasound Med. 2000;19 (2):69-72.

45. Food and Drug Administration. Guidance for industry and FDA staff-information for manufacturers seeking marketing clearance of diagnostic ultrasound systems and transducers. 2008. http://www.fda.gov/MedicalDevices/DeviceRegulationandGuid ance/GuidanceDocuments/ucm070856.htm. Accessed 7 Feb 2010

46. Rosenthal I, Sostaric JZ, Riesz P. Sonodynamic therapy-a review of the synergistic effects of drugs and ultrasound. Ultrason Sonochem. 2004;11(6):349-63. 